\title{
Stable isotope ratios in winter-grown feathers of Great Reed Warblers Acrocephalus arundinaceus, Clamorous Reed Warblers A. stentoreus and their hybrids in a sympatric breeding population in Kazakhstan
}

\author{
ELIZABETH YOHANNES, ${ }^{1 *}$ RAYMOND W. LEE, ${ }^{2}$ MARC C. JOCHIMSEN ${ }^{1}$ \& BENGT HANSSON ${ }^{3}$ \\ ${ }^{1}$ Stable Isotope Laboratory, Limnological Institute, University of Constance, D-78464 Constance, Germany \\ ${ }^{2}$ School of Biological Sciences, Washington State University, Pullman, WA 99164-4236, USA \\ ${ }^{3}$ Department of Biology, Lund University, SE-223 62 Lund, Sweden
}

\begin{abstract}
Analyses of the stable isotope composition of feathers can provide significant insight into the spatial structure of bird migration. We collected feathers from Great Reed Warblers Acrocephalus arundinaceus, Clamorous Reed Warblers A. stentoreus and a small sample of their hybrids in a sympatric breeding population in Kazakhstan to assess natural variation in stable isotope signatures and delineate wintering sites. The Great Reed Warbler is a long-distance migrant that overwinters in sub-Saharan Africa, whereas the Clamorous Reed Warbler performs a short-distance migration to the Indian sub-continent. Carbon $\left(\delta^{13} \mathrm{C}\right)$, nitrogen $\left(\delta^{15} \mathrm{~N}\right)$ and deuterium $(\delta \mathrm{D})$ isotope signatures were obtained from winter-grown feathers of adult birds. There were highly significant differences in $\delta \mathrm{D}$ and less significant differences in $\delta^{13} \mathrm{C}$ between Great and Clamorous Reed Warblers. Thus, our results show that the stable isotope technique, and in particular the deuterium $(\delta \mathrm{D})$ signal, resolves continental variation in winter distribution between these closely related Acrocephalus species with sympatric natal origin. The isotope signatures of hybrid Great $\times$ Clamorous Reed Warblers clustered with those of the Great Reed Warblers. Hence, a parsimonious suggestion is that the hybrids undergo moult in Afrotropical wintering grounds, as do the Great Reed Warblers. The observed $\delta \mathrm{D}$ values fell within the range of expected values based on available precipitation data collected at precipitation stations across the wintering continents of each species. However, the power to predict the winter origin of birds in our study system using these data was weak as the expected values ranged widely at this broad continental scale.
\end{abstract}

Keywords: carbon, deuterium, hybridization, migration, nitrogen, passerines.

Understanding the ecological and evolutionary processes underlying the geographical distribution of migratory birds requires knowledge of their movements and distribution throughout the year. Endogenous markers such as stable isotopes may be useful as a means of tracking animal movement and distribution, and the stable isotope composition of feathers has been widely applied to track

${ }^{*}$ Corresponding author.

Email: Elizabeth.Yohannes@uni konstanz.de migration patterns and delineate wintering quarters in birds (Hobson 1999, Rubenstein \& Hobson 2004, Veen et al. 2007, Chang et al. 2008, Ramos et al. 2009). Isotopic ratios of the local environment are incorporated into the growing feathers of birds during nutrient uptake at the nestling stage or later during the annual moult. The relative amount of stable carbon and nitrogen isotopes in the tissue can be used to assess xeric vs. mesic or marine vs. freshwater gradients, while the global patterns of deuterium in rainfall that transmit 
through the local food web provide a mechanism to track animal movements within and between continents (Marra et al. 1998, Hobson 2003).

The Great Reed Warbler Acrocephalus arundinaceus and the Clamorous Reed Warbler A. stentoreus are closely related passerines with similar behaviour and breeding ecology, and their breeding ranges partly overlap in the Middle East and southern Central Asia (Cramp 1992, del Hoyo et al. 2006). The Great Reed Warbler is a long-distance migrant and all populations are believed to overwinter in tropical Africa. In contrast, most Clamorous Reed Warbler populations are sedentary, but the breeding birds in Pakistan, Afghanistan and southern Kazakhstan undertake short-distance migration to the Indian sub-continent. Both species undergo moult at their wintering sites in late autumn and early winter (Cramp 1992, del Hoyo et al. 2006).

We compared the stable isotope ratios of carbon $\left(\delta^{13} \mathrm{C}\right)$, nitrogen $\left(\delta^{15} \mathrm{~N}\right)$ and deuterium $(\delta \mathrm{D})$ of winter-grown feathers of adult Great Reed Warblers and Clamorous Reed Warblers breeding sympatrically in Kazakhstan, Central Asia (Hansson et al. 2003). We also assessed the stable isotope signatures of a small sample of hybrid Great $\times$ Clamorous Reed Warblers from the same population to evaluate whether it is possible to distinguish their winter origin by applying stable isotope analyses. Moreover, using continental $\delta \mathrm{D}$ expectations for Africa and Asia, we attempt to assign winter-grown feathers of Great Reed Warblers, Clamorous Reed Warblers and their hybrids to their possible wintering origins. This would be valuable because, in migratory species, hybrid survival and fitness may be reduced as a result of an intermediate migration behaviour, leading to sub-optimal migration routes, patterns and wintering grounds (Berthold \& Querner 1981, Helbig 1991, Bensch et al. 1999, Veen et al. 2007).

\section{METHODS}

Between 14 and 19 May 2001, we examined Great Reed Warblers $(n=30)$, Clamorous Reed Warblers $(n=192)$ and their hybrids $(n=4)$ at Stone Lake, southern Central Kazakhstan $\left(42^{\circ} 49^{\prime} \mathrm{N}, 70^{\circ} 56^{\prime} \mathrm{E}\right)$, where both species breed (Hansson et al. 2003). The two species share the same reedbed habitat and show no clear habitat segregation. All birds examined were adults (i.e. at least 1 year old), and had survived at least one winter season.
During fieldwork, we encountered four birds with wing characteristics that were intermediate between the parental species, and whose identity could not be determined directly. Detailed morphological and molecular analyses later confirmed their hybrid origin (Hansson et al. 2003). Individual morphological measurements (wing length, primary projection, tail length, bill length and bill + head length) were taken (Hansson et al. 2003). One tail feather was collected from 21 Great Reed Warblers, 23 Clamorous Reed Warblers and three hybrid birds for stable isotope analyses.

To identify hybrids using molecular methods, we had previously evaluated allele length distributions of eight microsatellite loci and detected one diagnostic marker that showed no overlap in allele lengths between Great Reed Warblers and Clamorous Reed Warblers (Hansson et al. 2003). The microsatellites were amplified using PCR as described in Hansson et al. (2000) and Richardson et al. (2000). The species identity of the mothers of the hybrids was determined by sequencing a short fragment of the mitochondrial DNA that included the $3^{\prime}$-end of the control region, the tRNAPhe gene and the $5^{\prime}$-end of the 12S RNA gene, by using the primers BCML4 and $12 \mathrm{SH}$ (Mundy et al. 1996, Hansson et al. 2003). Two of the hybrids carried a Clamorous Reed Warbler mitochondrial sequence, whereas one carried a Great Reed Warbler sequence (Hansson et al. 2003). Thus, two of the three hybrids had resulted from mating between Clamorous Reed Warbler females and Great Reed Warbler males.

For the stable isotope analyses, feather sub-samples $(c .0 .35 \mathrm{mg})$ were weighed into $0.3 \times 0.5-\mathrm{mm}$ tin capsules to the nearest $0.001 \mathrm{mg}$, using a micro-analytical balance. Samples were then combusted in a Eurovector (Milan, Italy) elemental analyser. The resulting $\mathrm{CO}_{2}$ and $\mathrm{N}_{2}$ were separated by gas chromatography and admitted into the inlet of a Micromass (Manchester, UK) Isoprime isotope ratio mass spectrometer (IRMS) for determination of ${ }^{13} \mathrm{C} /{ }^{12} \mathrm{C}$ and ${ }^{15} \mathrm{~N} /{ }^{14} \mathrm{~N}$ ratios. Measurements are reported in $\delta$-notation $\left(\delta^{13} \mathrm{C}\right.$ and $\delta^{15} \mathrm{~N}$, respectively) relative to the Pee Dee Belemnite (PDB) for carbon and atmospheric $\mathrm{N}_{2}$ for nitrogen in parts per thousand deviations (\%o). Egg albumin was used as a laboratory standard for every 11 unknowns in sequence. Hundreds of replicate assays of internal laboratory standards (albumin) indicate measurement errors (sd) of $\pm 0.2 \%$. Feather deuterium $(\delta D)$ measurements were per- 
formed by applying high-temperature pyrolysis using the same elemental analyser interfaced to an IRMS as described above, calibrated against standardized keratin and hydrocarbon reference materials. Feather sub-samples $(0.35 \pm 10 \mathrm{mg})$ placed into silver capsules were left open for a period of more than 14 days to allow sample exchangeable hydrogen to equilibrate with the moisture in the laboratory air. Multiple samples of BWB-II (whale baleen) with a known non-exchangeable $\delta^{2} \mathrm{H}$ VSMOW (Vienna-Standard Mean Ocean Water) value were analysed, and compared with a commercially obtained keratin sample used as a routine standard. These standards indicated a precision of $\pm 3 \%$. Multiple routine replicate standards, with known non-exchangeable $\delta \mathrm{D}$ values, were used for correcting uncontrolled isotopic exchange between samples and ambient water vapour (Wassenaar \& Hobson 2000). Thus, values reported here are equivalent to non-exchangeable feather hydrogen (Wassenaar \& Hobson 2003).

We tested differences in mean feather isotope values between both species with two-sample $t$-tests for unequal sample sizes and equal variances, and Bonferroni adjusted the $P$-values to reduce a cumulative Type I error when successively testing three different isotope signatures, in SYSTAT Version 10 (SPSS Inc., Chicago, IL, USA).

To assess multivariate among-replicate differences we applied non-metric multidimensional scaling (NMDS), using Bray-Curtis similarity as a distance measure between stable isotope ratios of carbon $\left(\delta^{13} \mathrm{C}\right)$, nitrogen $\left(\delta^{15} \mathrm{~N}\right)$ and deuterium $(\delta D)$ in feathers of adult Great Reed Warblers and Clamorous Reed Warblers and their hybrids. We also employed NMDS to compare differences in biometric measurements (wing length, primary projection, tail length, bill length and bill + head length) of the parental and hybrid individuals. Because we did not take the whole set of biometric measurements for all birds captured, we here considered a subset of the data for which we had all the biometric and isotope measurements. Thus, we used wing length, primary projection, tail feather length, bill length and bill + head length measurements of the 45 birds (19 Great Reed Warblers, 23 Clamorous Reed Warblers and three male hybrids). NMDS is a non-linear ordination technique suitable for mapping multivariate ecological data on a two-dimensional space based on their ranked distance; hence, the position of data points (here individual birds) relative to each other corre- sponds to their similarity (Legendre \& Legendre 1998). NMDS values were calculated within the statistical software environment $\mathrm{R}$ with the packages vegan (Oksanen et al. 2010) and MASS (Venables \& Ripley 2002).

A priori predictions for variation in expected feather $\delta \mathrm{D}$ were evaluated using precipitation values from the GNIPS/ISOHIS $\delta$ D database (IAEA 2001) and isocline interpolated maps developed by Bowen et al. (2005). Because the wintering continents for both species have a year-long growing season, we used annual $\delta \mathrm{D}$ precipitation from stations located within each species' wintering range. For Great Reed Warbler, we used annual $\delta \mathrm{D}$ precipitation data from stations located throughout Africa while for Clamorous Reed Warbler, we used all available data from the South Asian subcontinent using stations located in Pakistan and India. We expected winter-grown feathers of Great Reed Warblers and Clamorous Reed Warblers to reflect the growing-season continental isotopic estimates for Africa and Indio-Asia, respectively.

\section{RESULTS}

Figure 1 shows the distribution of feather $\delta^{15} \mathrm{~N}$ and $\delta^{13} \mathrm{C}$ signatures of the two warbler species and their hybrids plotted against their respective $\delta \mathrm{D}$ values. The mean feather isotope values of the Great Reed Warblers $(n=21)$ and the Clamorous Reed Warblers $(n=23)$ differed significantly for two of three isotopes analysed: $\delta^{13} \mathrm{C}$ and $\delta \mathrm{D}$ $\left(\delta^{13} \mathrm{C}: t_{42}=3.073, \quad P_{\text {Bonferroni }}=0.011 ; \delta \mathrm{D}: t_{41}=\right.$ $11.988, P_{\text {Bonferroni }}<0.001$ ) while $\delta^{15} \mathrm{~N}$ values were not different between the species $\left(t_{42}=0.336\right.$, $P_{\text {Bonferroni }}=1.000$ ). Clamorous Reed Warbler isotope values also differed significantly from the hybrids in both $\delta \mathrm{D}$ and $\delta^{15} \mathrm{~N}\left(\delta \mathrm{D}: t_{24}=5.488\right.$, $P_{\text {Bonferroni }}<0.001 ; \delta^{15} \mathrm{~N}: t_{24}=3.180, P_{\text {Bonferroni }}=$ 0.012 ). In contrast, there was no significant difference between the hybrids and the Great Reed Warblers in any of the isotope signatures $\left(\delta^{13} \mathrm{C}\right.$ : $t_{22}=0.067, P_{\text {Bonferroni }}=1.000 ; \delta^{15} \mathrm{~N}: t_{22}=1.888$, $P_{\text {Bonferroni }}=0.217 ; \quad \delta \mathrm{D}: \quad t_{22}=0.879, \quad P_{\text {Bonferroni }}=$ 1.000), nor between the hybrids and the Clamorous Reed Warblers in $\delta^{13} \mathrm{C}\left(t_{24}=1.930, P_{\text {Bonferroni }}=\right.$ 0.196; Fig. 1).

Figure 2(a) shows an NMDS ordination plot of biometrics used to determine morphological differences between the respective parental species and hybrids, while Fig. $2(\mathrm{~b})$ shows the $\delta^{15} \mathrm{~N}, \delta^{13} \mathrm{C}$ and $\delta \mathrm{D}$ signatures of the parental and hybrid feathers. 

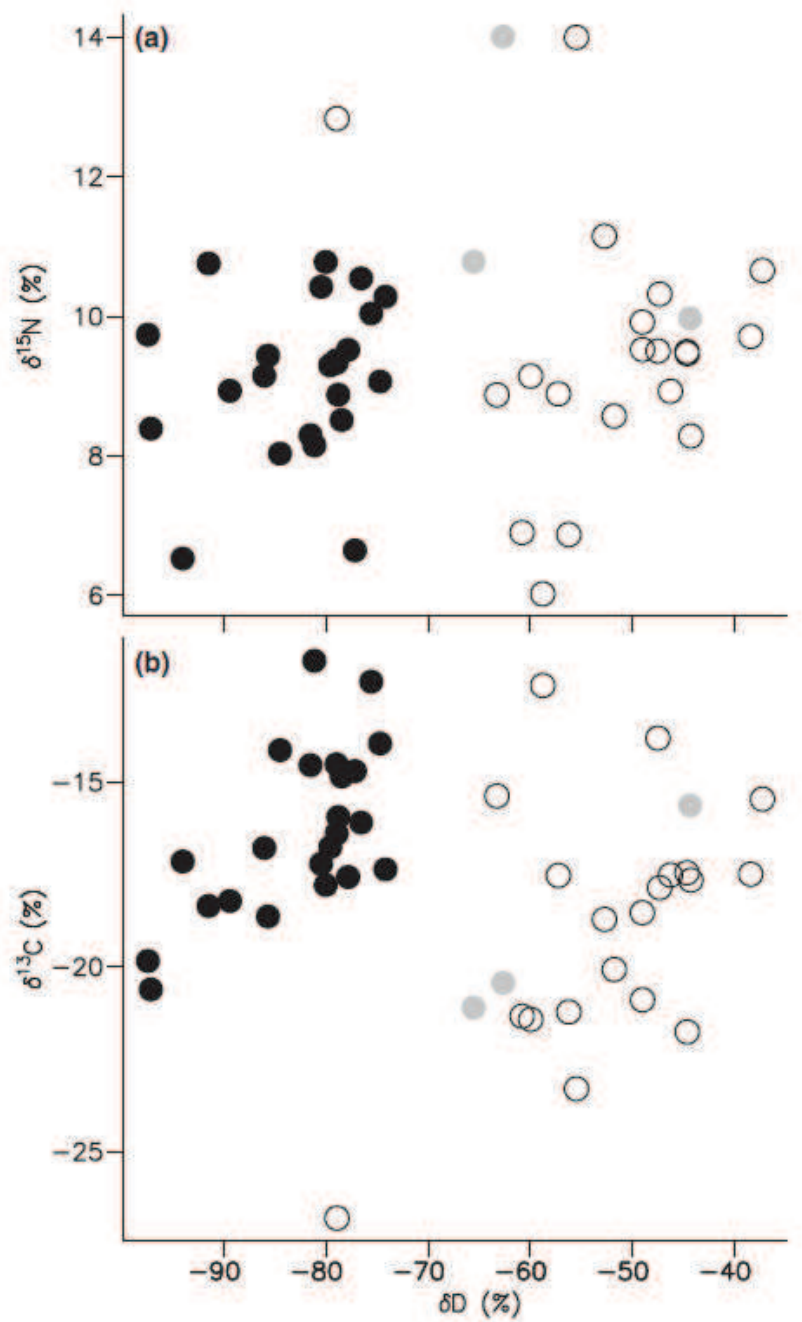

Figure 1. Stable isotope signatures $\left(\delta^{13} \mathrm{C}, \delta^{15} \mathrm{~N}\right.$ and $\left.\delta \mathrm{D}\right)$ in winter-grown feathers of adult Great Reed Warblers (white circles), Clamorous Reed Warblers (black circles) and their hybrids (grey circles) in a sympatric breeding population in southern Kazakhstan, Central Asia.

On biometrics, the birds clustered according to species, with hybrids showing an intermediate position. On isotope values, the two species were again distinct, but hybrids clustered with Great Reed Warblers. Mean feather isotope and biometric values per species and sex based on the data of all individual birds used in the NMDS plots are given in Table 1.

Precipitation $\delta \mathrm{D}$ values from the sites in Pakistan and India derived from the GNIPS/ISOHIS $\delta D$ database (IAEA 2001) indicate that feathers grown in this region are expected to display $\delta \mathrm{D}$ values in the range from approximately -120.0 to $+62.1 \%$ (Pakistan: -72.6 to $+38.6 \%$; India:
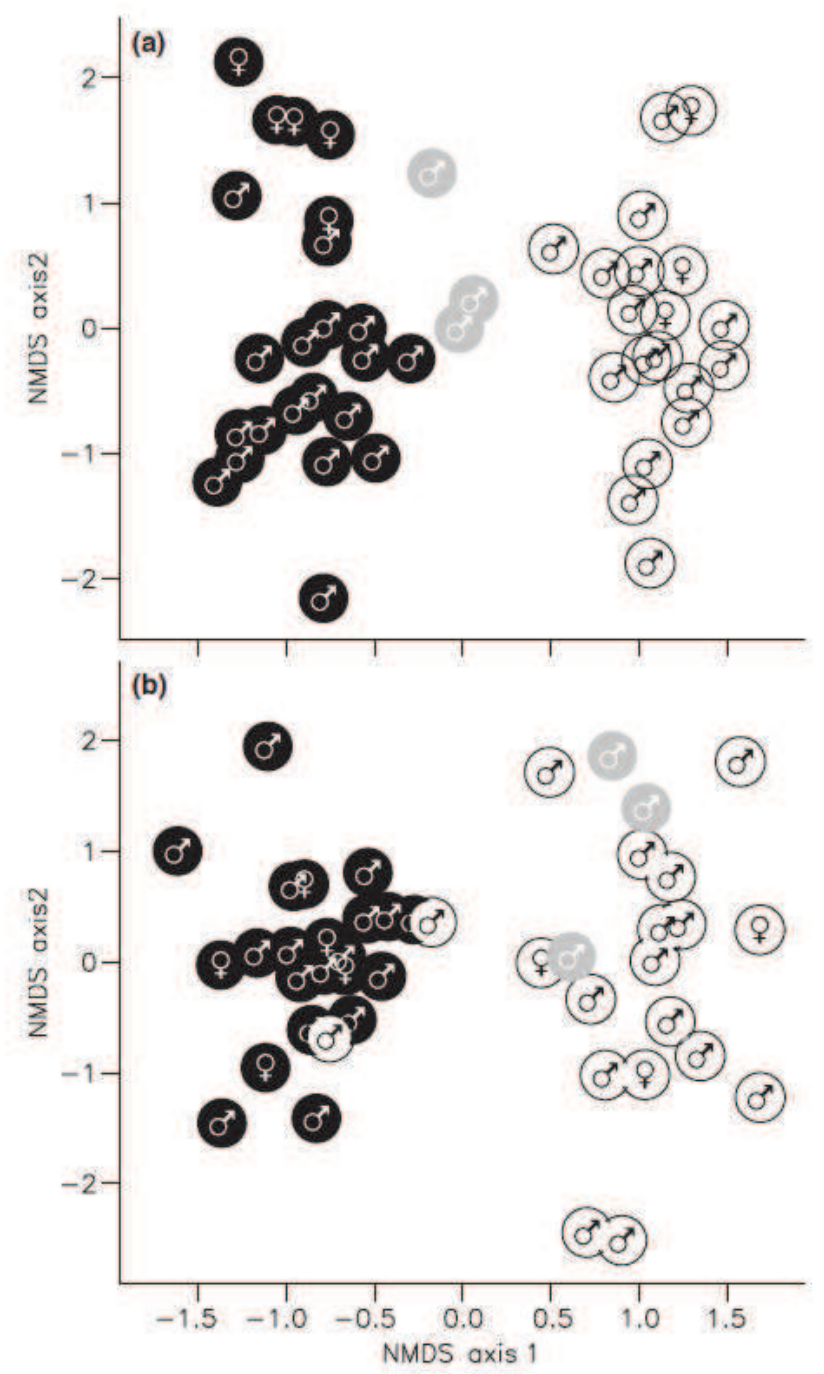

Figure 2. Non-metric multidimensional scaling (NMDS) ordination plot of parental species and hybrids representing (a) biometrics based on the similarity of wing length, primary projection, tail feather length, bill length and bill + head length, and (b) $\delta^{13} \mathrm{C}, \delta^{15} \mathrm{~N}$ and $\delta \mathrm{D}$ signatures. White, black and grey circles denote Great Reed Warblers, Clamorous Reed Warblers and their hybrids, respectively.

-120.0 to $+62.1 \%$ ). Precipitation $8 \mathrm{D}$ values from sites located in continental Africa range from approximately -63.0 to $+32.0 \%$. Based on isotopic continental maps (Bowen et al. 2005), the precipitation $\delta \mathrm{D}$ values for Africa overlap with those of India and Pakistan. Based on non-exchangeable $\mathrm{H}$ and corrected for fractionation (Wassenaar \& Hobson 2003), the precipitation values corresponding to species feather $\delta \mathrm{D}$ values were expected to range between -53.95 and $-12.3 \%$ in Great Reed Warblers, and between -72.5 and 
Table 1. Mean ( \pm se) biometric values and feather stable isotopes of Great Reed Warbler ( $A$. arund), Clamorous Reed Warbler ( $A$. stent) and their hybrids. These data were applied to generate biometric and feather isotope NMDS plots (Fig. 2).

\begin{tabular}{|c|c|c|c|c|c|}
\hline & $\begin{array}{l}\text { A. arund male } \\
\left(\begin{array}{ll}n & 16\end{array}\right)\end{array}$ & $\begin{array}{l}\text { A. stent male } \\
\left(\begin{array}{ll}n & 18\end{array}\right)\end{array}$ & $\begin{array}{l}\text { Hybrid male } \\
\qquad\left(\begin{array}{ll}n & 3\end{array}\right)\end{array}$ & $\begin{array}{l}\text { A. arund female } \\
\qquad\left(\begin{array}{ll}n & 3\end{array}\right)\end{array}$ & $\begin{array}{l}\text { A. stent female } \\
\begin{array}{ll}n & 5)\end{array}\end{array}$ \\
\hline Wing length (mm) & $98.50( \pm 0.54)$ & $93.53( \pm 0.37)$ & $94.67( \pm 0.17)$ & $93.83( \pm 0.93)$ & $87.80( \pm 0.37)$ \\
\hline Primary projection (mm) & $29.09( \pm 0.37)$ & $21.14( \pm 0.33)$ & $24.50( \pm 0.29)$ & $29.33( \pm 0.88)$ & $20.70( \pm 0.30)$ \\
\hline Tail length (mm) & $77.94( \pm 0.70)$ & $83.69( \pm 0.70)$ & $78.00( \pm 0.58)$ & $73.33( \pm 0.33)$ & $76.20( \pm 0.73)$ \\
\hline Bill (mm) & $12.75( \pm 0.12)$ & $14.21( \pm 0.10)$ & $13.67( \pm 0.44)$ & $12.37( \pm 0.38)$ & $14.52( \pm 0.22)$ \\
\hline Bill to head (mm) & $44.16( \pm 0.16)$ & $46.32( \pm 0.16)$ & $46.37( \pm 0.42)$ & $43.27( \pm 0.39)$ & $45.56( \pm 0.41)$ \\
\hline$\delta^{13} \mathrm{C}(\%)$ & $18.64( \pm 0.89)$ & $16.53( \pm 0.55)$ & $19.05( \pm 1.72)$ & $18.36( \pm 0.85)$ & $15.58( \pm 0.85)$ \\
\hline$\delta^{15} \mathrm{~N}(\%)$ & $9.25( \pm 0.42)$ & $9.24( \pm 0.25)$ & $11.59( \pm 1.23)$ & $9.06( \pm 0.34)$ & $8.76( \pm 0.68)$ \\
\hline$\delta \mathrm{D}(\%)$ & $52.56( \pm 2.53)$ & $82.93( \pm 1.70)$ & $57.54( \pm 6.64)$ & $49.16( \pm 5.59)$ & $81.52( \pm 2.98)$ \\
\hline
\end{tabular}

$-49.2 \%$ in Clamorous Reed Warblers. Therefore, for these two species the feather $\delta \mathrm{D}$ values (Table 1) fell within the range of those predicted by the GNIPS/ISOHIS $\delta \mathrm{D}$ database for wintering grounds in Africa and Asia, respectively. The feather $\delta \mathrm{D}$ in the three hybrids $(-40.57,-37.68$ and $-19.37 \%$ ) corresponded to regions in Africa (in line with the assumption that the hybrids undergo moult in Africa), but also to India and Pakistan.

\section{DIscussion}

Our results demonstrate that the moulting feather isotope values $\left(\delta^{13} \mathrm{C}\right.$ and $\left.\delta \mathrm{D}\right)$ differed between the two sympatric species, with a strong indication that birds of these two closely related Acrocephalus species migrated to overwintering sites in subSaharan Africa and the Indian sub-continent, respectively. As expected, the two species showed differences in their biometrics sufficient to group them in separate clusters with higher similarity within than between the two species (Hansson et al. 2003).

Hence, stable isotope techniques can be applied as a powerful method to evaluate the wintering origins of returning migratory Acrocephalus populations adopting the Palaearctic-African or the Palaearctic-Indian migration routes, respectively. The relative amounts of $\delta^{13} \mathrm{C}$ and $\delta^{15} \mathrm{~N}$ that are incorporated into the growing feathers of birds during nutrient uptake can be used to assess habitat characteristics and place in the food chain during moult, and the global patterns of $\delta \mathrm{D}$ in rainfall that transmit through the local food web can provide information about animal movements within and between continents (Marra et al. 1998, Hobson 2003). Accordingly, the pronounced difference in $\delta \mathrm{D}$ and $\delta^{13} \mathrm{C}$ between Great and
Clamorous Reed Warblers was expected from the species' widely separated overwintering areas (Cramp 1992), whereas the similar $\delta^{15} \mathrm{~N}$ may suggest that they utilize similar dietary sources and habitats, as would be predicted from the similarity of their ecology.

The isotope ratios in feathers of the hybrids were similar to those of the Great Reed Warbler (Figs 1 and 2), and despite the small sample size ( $n=3$ hybrids) there was a statistically significant difference between the hybrids and Clamorous Reed Warblers in $\delta \mathrm{D}$ and $\delta^{15} \mathrm{~N}$. Although these results should be interpreted with caution due to the very small sample size, a parsimonious suggestion from the feather isotope results, strengthened by the ordination analysis, is that these hybrids underwent moult in Afrotropical wintering grounds, as do the Great Reed Warblers. The NMDS ordination plot of biometrics used to determine $\delta^{15} \mathrm{~N}, \delta^{13} \mathrm{C}$ and $\delta \mathrm{D}$ signatures of the parental and hybrid feathers (Fig. 2b) suggest that two male Great Reed Warblers may have migrated or moulted in Asia (or on isotopically similar moulting grounds). However, this suggestion is not supported by the patterns in the two-dimensional single-isotope plots in which the Clamorous Reed Warblers form highly uniform clusters in both cases (Fig. 1).

Comparison of feather $\delta \mathrm{D}$ values with precipitation $\delta \mathrm{D}$ values from sites from India, Pakistan and continental Africa support the hypothesis that Great Reed Warbler feathers are grown on African wintering grounds, whereas Clamorous Reed Warbler feathers are grown on Indo-Asian wintering grounds. However, it should be noted that the GNIPS/ISOHIS $\delta \mathrm{D}$ data sources hold large datasets, many of which are lacking spatio-temporal continuity and some regions are not evenly 
represented. Moreover, the long-term GNIPS database and isocline maps for Africa and Asia depict a highly dynamic seasonal pattern in precipitation values. In addition, the rate at which local food webs reflect the precipitation $\delta \mathrm{D}$ of a given period is not known. This precludes direct comparison of precipitation with $\delta \mathrm{D}$ values expected in recently grown feathers. Nevertheless, our expectations were based on the best available data over these broad geographical locations. Physiological and environmental sources of variation in feather $\delta \mathrm{D}$ from species of different geographical origin need to be considered before assigning individuals of unknown origin to distinct geographical regions (e.g. Wunder \& Norris 2008, Betini et al. 2009).

In a recent stable isotope analysis, Veen et al. (2007) showed that the isotope signal of hybrid Pied $\times$ Collared Flycatchers (Ficedula hypoleuca $\times$ F. albicollis) in a sympatric breeding population in northern Europe clustered with that of the Pied Flycatcher, and not with that of the Collared Flycatcher. Pied Flycatchers overwinter in western and central Africa, and the Collared Flycatcher in eastern and southern central Africa (Cramp 1992). It was argued that dominant expression in hybrids' migratory traits from one of the parental species (in this case the Pied Flycatcher) explained the high annual survival of the hybrids and thus substantially reduced the extrinsic post-zygotic costs of hybridization (Veen et al. 2007). Interestingly, in the previous morphological and molecular study of Great and Clamorous Reed Warblers and their hybrids (Hansson et al. 2003), we observed that some wing characteristics (wing length and primary projection) of the hybrids are intermediate between the parental species, suggesting co-dominant expression of those traits. On the other hand, the hybrids had short tails and fewer primaries with emargination than the Great Reed Warblers and a large bill-head extension like Clamorous Reed Warblers (Hansson et al. 2003, Table 1), which suggest that some traits may well be dominantly expressed in these Acrocephalus warblers. The adult hybrids that we examined had spent at least one winter season in their annual life cycle. Adult hybrids are rare and as we do not know the exact proportion of hybrids at the nestling stage, we cannot exclude the possibility that hybrids with intermediate migration pathways might occur and that they might be selected against. The three sampled individuals had in any case been able to survive the first winter and both outward and return migrations. In two Willow Warbler subspecies breeding in northern Europe (Phylloscopus trochilus trochilus and P. t. acredula), an intermediate migration route potentially taken by hybrids would lead them straight over the central Sahara desert where many may succumb as a result of food and water shortage; this has been suggested to explain the low survival of hybrids in that species (Bensch et al. 1999).

As documented for central European Blackcaps Sylvia atricapilla (Rolshausen et al. 2009), improved wintering conditions related to human activities or local environmental changes could have promoted the recent establishment of novel migratory routes and wintering grounds. However, our data suggest that the hybrids we examined have not adopted novel migration schemes, and that they use non-breeding grounds isotopically similar to those of the Great Reed Warbler.

In summary, the recovery of viable, adult hybrids between Great Reed Warblers and Clamorous Reed Warblers is unusual, and there is no evidence that documented hybridization between these species occurs elsewhere. As mentioned above, the species differ only slightly in morphology, and very few plumage differences exist between them (the Great Reed Warbler is greyishbrown on the mantle, whereas the Clamorous Reed Warbler is buffish-brown). Hybrids between such morphologically almost uniform species cannot be recognized easily, and thus hybrids are cryptic to humans, unless diagnosed using molecular techniques. The two species have adapted to different migration routes and wintering sites, and the somewhat longer, more pointed wing of the Great Reed Warbler reflects this species' longer migration route. The hybrids have intermediate wing shape (primary projection) and thus a wing that should not be optimally suited to long-distance migration (e.g. Bensch et al. 1999). Yet, the isotopic evidence presented here suggests that the hybrids perform a long-distance migration and moult in a similar wintering ground to that of Great Reed Warblers. That the hybrids were able to return to their breeding grounds suggests that they have a functional migratory behaviour. However, we have studied a very small number of hybrids that successfully returned to their breeding grounds and future analyses in this reed warbler population are necessary to distinguish whether all hybrids avoid intermediate migration routes and sub-optimal wintering areas by adopting the migratory directions of one of the 
parental species, or whether hybrids frequently use intermediate migration pathways and are thereby selected against. This will require data on the proportion of hybrids at the nestling stage, annual survival, isotope analyses in winter-grown feathers on a sufficient number of additional hybrids and ideally geographical position data from individually tracked birds.

We thank Edward Gavrilov, Andrey Gavrilov and Anna Karin Olsson for logistic support and assistance in the field. We are grateful to Ioanna Salvarina for valuable discussions. This study was supported by grants from the Swedish Research Council, the Royal Swedish Academy of Science (Ahlstrand's foundation), the Knut and Alice Wallenberg Foundation and National Science Foundation grant DBI 011620. We are grateful to Kenji Adachi and the members of the Webster and Schwabl Labs (WSU) for valuable assistance in the laboratory. The fieldwork was approved by the Animal Marking Centre, Institute of Zoology, Kazakhstan.

\section{REFERENCES}

Bensch, S., Andersson, T. \& Åkesson, S. 1999. Morphological and molecular variation across a migratory divide in Willow Warblers, Phylloscopus trochilus. Evolution 53: 19251935.

Berthold, P. \& Querner, U. 1981. Genetic basis of migratory behavior in European warblers. Science 212: 7779.

Betini, G.S., Hobson, K.A., Wassenaar, L.I. \& Norris, D.R. 2009. Stable hydrogen isotope $(\delta D)$ values in songbird nestlings: effect of diet, temperature, and body size. Can. J. Zool. 87: 766772.

Bowen, G.J., Wassenaar, L.I. \& Hobson, K.A. 2005. Global application of stable hydrogen and oxygen isotopes to wildlife forensics. Oecologia 143: 337348.

Chang, Y.M., Hatch, K.A., Ding, T.S., Eggett, D.L., Yuan, H.W. \& Roeder, B.L. 2008. Using stable isotopes to unravel and predict the origins of Great Cormorants (Phalacrocorax carbo sinensis) overwintering at Kinmen. Rapid Commun. Mass Spectrom. 22: 12351244.

Cramp, S. 1992. Handbook of the Birds of Europe, the Middle East and North Africa. Oxford: Oxford University Press.

Hansson, B., Bensch, S., Hasselquist, D., Lillandt, B.-G., Wennerberg, L. \& von Schantz, T. 2000. Increase of genetic variation over time in a recently founded population of Great Reed Warblers (Acrocephalus arundinaceus) revealed by microsatellites and DNA fingerprinting. Mol. Ecol. 9: 15291538.

Hansson, B., Gavrilov, E. \& Gavrilov, A. 2003. Hybridisation between Great Reed Warblers Acrocephalus arundinaceus and Clamorous Reed Warblers A. stentoreus: morphological and molecular evidence. Avian Sci. 3: 145151.

Helbig, A.J. 1991. Inheritance of migratory direction in a bird species: a cross-breeding experiment with SE- and SWmigrating Blackcaps (Sylvia atricapilla). Behav. Ecol. Sociobiol. 28: 912.
Hobson, K.A. 1999. Tracing origins and migration of wildlife using stable isotopes: a review. Oecologia 120: 314326.

Hobson, K.A. 2003. Making migratory connections with stable isotopes. In Gwinner, E. \& Sonnenschein, E. (eds) Avian Migration: 379 391. Berlin: Springer-Verlag.

del Hoyo, J., Elliott, A. \& Christie, D.A. 2006. Handbook of the Birds of the World. Barcelona: Lynx Edicions.

IAEA 2001. Isotope Hydrology Information System. The ISOHIS database. Available at: http://www-naweb.iaea.org/napc/ih/ IHS resources gnip.html (accessed 29 January 2011).

Legendre, P. \& Legendre, L. 1998. Numerical Ecology. Amsterdam: Elsevier.

Marra, P.P., Hobson, K.A. \& Holmes, R.T. 1998. Linking winter and summer events in a migratory bird by using stablecarbon isotopes. Science 282: 18841886.

Mundy, N.I., Winchell, C.S. \& Woodruff, D.S. 1996. Tandem repeats and heteroplasmy in the mitochondrial DNA control region of the Loggerhead Shrike (Lanius ludovicianus). J. Hered. 87: 2126.

Oksanen, J.F., Blanchet, G., Kindt, R., Legendre, P., O'Hara, R.G., Simpson, L.G., Solymos, P., Henry, M., Stevens, H. \& Wagner, H. 2010. Vegan: Community Ecology Package. R package version 1.17-4. http://CRAN.Rproject.org/package vegan (accessed 29 January 2011).

Ramos, R., Gonzalez-Solis, J. \& Ruiz, X. 2009. Linking isotopic and migratory patterns in a pelagic seabird. Oecologia 160: 97105.

Richardson, D.S., Jury, F.L., Dawson, D.A., Salgueiro, P., Komdeur, J. \& Burke, T. 2000. Fifty Seychelles Warbler (Acrocephalus sechellensis) microsatellite loci polymorphic in Sylviidae species and their cross-species amplification in other passerine birds. Mol. Ecol. 9: 21552234.

Rolshausen, G., Segelbacher, G., Hobson, K.A. \& Schaefer, H.M. 2009. Contemporary evolution of reproductive isolation and phenotypic divergence in sympatry along a migratory divide. Curr. Biol. 19: 20972101.

Rubenstein, D.R. \& Hobson, K.A. 2004. From birds to butterflies: animal movement patterns and stable isotopes. Trends Ecol. Evol. 19: 256263.

Veen, T., Svedin, N., Forsman, J.T., Hjernquist, M.B., Qvarnström, A., Hjernquist, K.A., Traff, J. \& Klaassen, M. 2007. Does migration of hybrids contribute to post-zygotic isolation in flycatchers? Proc. Biol. Sci. 274: 707712.

Venables, W.N. \& Ripley, B.D. 2002. Modern Applied Statistics with $S$. New York: Springer.

Wassenaar, L.I. \& Hobson, K.A. 2000. Stable-carbon and hydrogen isotope ratios reveal breeding origins of Redwinged Blackbirds. Ecol. Appl. 10: 911916.

Wassenaar, L.I. \& Hobson, K.A. 2003. Comparative equilibration and online technique for determination of non-exchangeable hydrogen of keratins for use in animal migration studies. Isotopes Environ. Health Stud. 39: 211217.

Wunder, M.B. \& Norris, D.R. 2008. Improved estimates of certainty in stable-isotope-based methods for tracking migratory animals. Ecol. Appl. 18: 549559. 